\title{
Investigating the Effects of "Philosophy for Children" Program on the Reduction of Psychosomatic Disorders Symptoms in 9-11 age boys
}

\author{
Akram Shatalebi $^{* 1}$, MehrnooshHedayati ${ }^{2}$ \\ ${ }^{1}$ Master since of General psychology, Azad University, Iran \\ Address: No.7 Ardeshir Ave., Hashtbehesht Ave., Dr.Fatemi St., Tehran, Iran \\ Mobile: (+98) 9366903466, Tell: (+98) 21-88984466 \\ ${ }^{2}$ Department of philosophy for children, Institute for Humanities and Cultural Studies, Tehran, Iran \\ Address: Kordestan Highway, Tehran, Iran \\ Mobile: (+98)9123580198 \\ Email: ${ }^{1}$ psy_shatalebi@yahoo.com, ${ }^{2}$ mehrnooshhedayati@yahoo.com \\ Corresponding Author
}

Keywords: "Philosophy for Children" Program, community of inquiry, psychosomatic disorders, anxiety disorders

\begin{abstract}
This study is investigating the impact of "Philosophy for Children" Program on the reduction of the symptoms of psychosomatic disorders in children aged 9 to 11 years in Iran. The sample of the study consists of 45 primary school boy students who were randomly selected using multistage random cluster sampling from among 19 districts of Education. This is a Quasiexperimental method research with experimental and control groups. Research tool in this study was Achenbach questionnaire form YSR (Youth Self-report). At first, using this questionnaire, all third and forth graders in two schools were selected by screening in which 45 ones got a score which showed psychosomatic disorders that all of them were eager to take part in the study. The test group, during a 12 sessions in a week, for 1 hour, participated in community of philosophical inquiry- the method of "Philosophy for Children" Program- with a training coach. After the end of the sessions, Achenbach's re-test, on both control and test groups, was taken to determine the effect of holding the "Philosophy for Children" Program on psychosomatic disorders. The results of this study showed that the implementation of this program has a significant effect in reducing symptoms of psychosomatic disorder of test group.
\end{abstract}

\section{INTRODUCTION}

Kids encounter stress and problems in many areas of their natural life which are not bad if they are normal and even learning how to master these conditions and face with them will help to grow emotional and individual recognition of the person. Although the appropriate and normal level of anxiety is considered part of anadolescent's life, the pathological anxiety creates problem in thenormal lives and academic performance of person;the chronic types have devastating effects on the psychological and physical health of person(Fergusson,1993). Sometimes children and adolescentsare facing with severe challenges and chronic stress which they are not able to dominate and find ways of dealing with; criteria such as parental divorce, loss of a parent or close relative, migration, violence, discrimination. Unfortunately, the high rate of anxiety disorders of students in the schools and during their study period indicatesstressful conditions and factors in educational environments. Inappropriate treatment oftraining staff, violence and bullying in the school environment, peer'sinferiority behaviors, inability to approaching and finding friend, score-based assessment, the prevalence of unhealthy academic competition, asymmetric relationship between students and teachers, lack of assertiveness and providing ideas and creativity of students, and many other reasons cause chronic anxiety during the academic year.

Children show different reactions to such situations; some match with them well and even welcome these stresses, and some of them escape from it; some, in response to these conditions, show different emotional conditions such as anger, sadness, and frustration. But other groups of children and adolescents show their reaction to stressful situations through developing health 
problems. In cases which the mental events and stressful situations closely relate with symptoms of physical and psychological disorders, so that the mentioned psychological factors are effective in the onset and exacerbation of these physical symptoms, the term "psychosomatic disorders" can be used for these forms of disease (Behdani, 2012: 294).

As classified, the fourth version of Diagnostic and Statistical Manual(DSM-IV), "somatoform disorders" are disorders which psychological factors play an important role in creating, stimulating, and lasting physical and body symptoms (Flammer\&Alladin, 2007). These disorders are caused by biological, psychological, and social factors (Walker \&Forness\& Kauffman, 2001: 24) and include gastrointestinal diseases, cardiovascular diseases, skin diseases, cancer diseases, sexual diseases, and musculoskeletal and infectious diseases (Wellman, 1998: 219). This disorder is common in all ages and is also highly common among students. Prevalence of anxiety disorders among students is reported between 10 to 20 percent (Kendall, et al, 2010), and this problem is estimated to be more than other neurological and psychiatric disorders ofstudents (Kashani, Orvaschel, 1990).

In psychosomatic disorders, the symptoms are very real for the child, but the doctor does not care for its diagnosis.Young children are not able to describe the exact pain and feel more fatigue; but older students are more accurate to describe the pain in detail;sometimes this pain is repeated for a short time and sometimes periodically. Headache, stomachache, neurobiological disorders such as blinking, ataxia, paralysis, or epilepsy, feeling of body dysmorphic, backache, fatigue, muscle weakness, and, in girls, due to early hormonal changes, may have symptoms such as anxiety, anorexia and pain (Thayer \&Brosschot, 2005).

Academic problems, academic-communication failure at school, social isolation, anxiety and behavioral problems can also affect on psychosomatic symptoms of student. Research shows that children who are bullied by their school staff or their peers at school are more likely to suffer from psychosomatic disorders (Gini, Pozzoli, 2013). Since the prevalence of the bullying phenomenon at schools is high and involves almost all the children (Hedayati, Zaribaf, 2011), taking strategies leading to reduce stress in academic environment can be effective in controlling students' psychosomatic disorder symptoms. Psychosomatic disorders are anxiety disorders which are prevalence among students and creates problem for their active participation and academic performance.

Currently, there are several approaches to treat psychosomatic disorders. An effective approach for the treatment of psychosomatic disorders is cognitive behavioral approach. Cognitive behavioral treatments include strategies designed for changing the thinking, attitude, and behavior of people suffering from disorders. In this method, it is tried to, through affecting on the alert intellectual pattern of the patient, his thoughts and actions are modified (Fessler et al., Translated by Parsa,2005: 25). Bahrami and Rezvan (2007), in their study, proved the relationship between anxiety disorders and metacognitive beliefs of students.

As it was previously mentioned, researchers believe that one of the most important types ofeducationalanxieties of students is psychosomatic disorders, which leads to increasing educational fall and disgust of students from studying. Students, in the teacher-centered and memory-raising schools, do not have enough time for discussion about concerned- issues and pondering about things that are really important to them, and because they do not have a chance to test their own ideas and beliefs, their distinctive power between the logical and irrational thoughts is minimized. This leads children to find the school an unfamiliar environment in which his only duty is to win the approval of his parents and teachers. Child goes to school with a passion and a large volume of questions, but he faces with some investigative questions which have the same repetitive answers; long-term experience in this area often leads to anxiety disorders, which generally shows itself through physical symptoms.

Educational approach, which changes the authoritative and unattractive space to respectfuldialogueand reflective space, in which students have reasonable argument for all opinions and thoughts, can lead to changes in children's cognitive and meta-cognitive states. Traditional educational environment which forces children to keep silence and to memorize a set of nonfunctional knowledge, will associate valuable years of children's life with anxiety. This anxietywill 
be further, when the child is forced to suppress his intellectual questions and ambiguities and finds the only important factor in scoreswhich measure hisknowledge memory(Sadeghian, 2010: 41).

The curriculum of philosophy for children is an approach based on changing the authoritative classroom space to intellectual and community of philosophical inquiry to promote democracy and independent thinking in students. Founders of philosophical program for children believe that teaching philosophical story to children in the communities of inquiry is through the promotion of philosophicaldialogue, in Socratic Method, and, in fact, has an investigative approach to learning (Lipman, Sharp \&Oscanyan, 1980). In this program, the story is used to fascinate stimulating and encouraging tools of thinking, because the founders of the program believe that the best tool to teach thinking to children is using the story. Story creates metaphorsfor real life of human beings which will link the people to it. The important feature of this metaphor is focused around a specific character who has motivation and purpose and faces with barriers to reach his purpose, which shapes the plot of the story. The story of the fighting of this character and the events which happen to him relates to the reader too (Haven, 2007:4) and makes the reader to think. What is depicted in the story is more or less similar to what a person can experience in his real life (Fisher, 2004: 136). One of the cognitive correction methods of children is when children listen to the story and express their personal thoughts and ideas, which may be effective in smoothing to the Psychosomatic symptoms (Fessler et al., Translated by Parsa, 2005: 25).

Mathew Lipman (2003), the founder of "philosophy for children" program believes the main problem of students in the school environment is that they are inundated with factual information that seems jumbled, pointless, and unconnected to their lives. He mentioned that traditional educational systemnurturestudents who have lack of the logical reasoning, and judgmentability. He maintains that philosophical story and dialogue is the best way to foster thinking; in his idea, philosophy does not mean history and philosophical ideas of thinkers and philosophers but it is an education which usesphilosophical methodsto force the mind of child to attempt so as torespond the need and longing for meaning. In the philosophical program for children, he changes dry atmosphere tocommunity of philosophical inquiry to change the school and school period from dictatorship to democracy; as a result, children explore the educational atmosphere to be a place to researchtheirmain questions and test their ideas and beliefs. In such an atmosphere, instead of being condemned to give"specific answer" to the question of teachers, the entire class is involvedin thoughtful questions in which any idea could guide individuals toachieveresponses; so, the child find his idea worthy to mention and would not censor himself. This lead to improve child's selfesteem (Hedayati, 2010 a) and minimizes the anxiety of participating in discussions.

Also, promoting philosophical educational approach for children improves personal attributes, such as the need to listen and to be heard, respect and dignity, confidence to talk about ideas, engaging with others and modifying them and self-modification, and, in spite of improving relations between individual students' intellectual skills (Hedayati, 2010 b;Kalantari, 2009; Mar'ashi, 2007), it creates an atmosphere free from bullying and violence in educational environments (Hedayati, Zaribaf, 2012).

Therefore, it is expected that the learning environment,which triggers cognitive development and wisdom in children, could also reduce environmental stress and inner anxiety. Sincepsychosomatic disorders are in the category of anxiety disorders, and psychologists believe anxiety to be greatly influenced by the way people think about themselves, their abilities and interpretation of difficulties, and as the most important engagement goal incommunity of philosophical inquiryis to grow cognitive and meta-cognitive development in children, this study seeks to determine whether participation in community ofinquiry and dialogue based on philosophical stories can lead to the reduction of the symptoms of psychosomatic disorders in children. 


\section{THE PURPOSE OF THE STUDY}

The overall goal of this research is to determine the effect of logicaldialoguein community of philosophical inquiry on the reduction of the symptoms of psychosomatic disorders in children aged 9 to 11 years in Tehran.

\section{POPULATION, SAMPLE AND SAMPLING}

In this study, population consists of all female students aged 9 to 11 years who were present in the primary schools of 19 districts of Education in the academic year 2012-13 in Tehran. For sampling, at first, district 5 was selected through multi-stage random clustering sampling from among 19 districts of Tehran Education, and, then, two schools in this area, the fifth and sixth classes of each, were chosen;afterwards, Achenbach's Youth self-report (YSR) test was given all children aged 9 to 11 in this schools. Screening the results indicated that $58 \%$ of the children in obtained scores higher than the cut line (7) in Achenbach's test. Finally,from among the 58 students whose scores were above the cut line, 45 students who were willing to participate in this project were randomly divided intotest and control groups.

\section{TOOLS AND METHODS OF DATA COLLECTION}

In this study, to investigate the psychosomatic disorders of students, Self-report (YSR) from Achenbach system of empirically based assessment (ASEBA) was used. Achenbach system of empirically based assessment (ASEBA) is a multi-axial model which provides a framework for organizing and integrating experimental data from different data sources. Information is gained from three sources of parents, teachers, and children. Information of three questionnaires is parallel and can also be used alone, and, certainly, all three forms can be considered complementary. These scales are: Child Behavior Checklist (CBCL) filled by parents. Self-Report Questionnaire (YSR), which will be completed by the student; and Teachers Report Form (TRF); because, in self-report form, the person has understood the reports of his situation and mood. In this study, using other forms was not required.

The questionnaire assesses emotional-behavioral problems as well as academic and social capabilities and competencies completed in 20 to 25 minutes (Achenbach \&Rescorla, 2001: 16). Based on the factor analysis performed on the questions about emotional-behavioral problems of all three forms, measures or tests were extracted and named measure based on experience. Measures based on experience were all the same in all three forms and are respectively: anxiety/ depression, withdrawal/ depression, somatic complaints, social problems, disorders of thought content, attention problems, rule breaking behavior; aggressive behavior, internalizing, externalizing, and general problems.

Studies have shown that there is consistency and relationship between DSM- IV diagnoses and ASEBA scale (Achenbach \&Rescorla, 2001: 16). Using the questions which, according to the ideas ofexperienced psychiatrists and psychologists, have much consistency much with diagnostic DSM categories, some measures were raised for scoring CBCL, YSR, and TRF. Measures based on DSM of all 3 forms were exactly the same as following: behavioral problems, ADHD, emotional problems, anxiety, coping behavior problems, physical problems. In this study, the questions related to the scale of psychosomatic are used. Each of the test material was graded in a three-degree scale $(0,1$, and 2). Two cut-off points were introduced for this test by various researchers (grades 9 and 7). In this study, the cut-off score of 7 is used. This questionnaire has high reliability and validity. Achenbach and Rescorla, in a study conducted on 105 children,reported thereliability factor $0 / 85$ for this test. In IranMinaee and colleagues (2006) performed Achenbach questionnaire on 1437 students in Tehran. The findings of the research show that all three forms have reliability and validity, and one can certainly use them to measure behavioral-emotional disorders in children and adolescents aged 6-18 years old. Self-report reliability coefficient was estimated to be 0/63 in this survey. 


\section{RESEARCH METHODOLOGY}

The present research is an applied one. This is a quasi-experimental study, a pretest-posttest one with control group and random assignment (Delavar, 2006). In this study, the dependent variable (psychosomatic disorders) was measured before and after the implementation of the independent variable (philosophical inquiry). So, students in the test group were participated for 12 60-minute sessions (one session per week) in community of philosophical inquiry and discussed freely about intellectual stories. This program, according to meetings, was held as follows:

Preliminary session was devoted to the introduction of teaching philosophy program to children and explaining the purpose of performing this method. For the students to learn more about this method, some exercises were provided to them. Next sessions, children sat, like a circle, around the researcher and read stories with the themes of fear, anxiety, anger, prejudice, friendship, and other topics related to the real life of students which could reflect their anxiety and psychosomatic symptoms. At the end of each story, they were asked to process their uncertainties and subjective questions in groups of 2-3 people, and write the best question, with the name of the group, on the board. Then, the facilitator helped them to choose the best question that encouraged discussion. Then, all the students were asked to express their opinion in response to the question; the ideas of each student, with his name, were written on the board and the students were asked to speak about their ideas through providing the evidence. Stories and, especially the activities and exercises after that, encouraged the children to think about irrational beliefs and false judgments and evaluate their thoughts with other children.

\section{RESEARCH FINDINGS}

In table 1 , the statistical description of the pre-test and post-test scores of "psychosomatic disorders" of children under study has separately been proposed. According to the provisions, the mean of the test scores of "psychosomatic disorder" for children under study is $9 / 16$ in the test group and 7/08 in the control group. Also, the mean of scores of the test group in post-test is $3 / 56$ and in control group is $6 / 48$. Based on the above results, the mean scores of "psychosomatic disorders" of testgroup in post-test have decreased but, in the control group, the mean scores of psychosomatic disorders in children are almost fixed.

Table 1. Statistical Description of the Pre-test and Post-test Scores of "psychosomatic disorder" According to the Groups.

\begin{tabular}{|l|l|l|l|l|l|l|}
\hline \multicolumn{2}{|c|}{ Psychosomatic disorders } & \multicolumn{3}{|l|}{ Descriptive Statistics } & $\begin{array}{l}\text { Central } \\
\text { Index }\end{array}$ & $\begin{array}{l}\text { Dispersion } \\
\text { index }\end{array}$ \\
\cline { 3 - 7 } & Number & Minimum & Maximum & Mean & $\begin{array}{l}\text { Standard } \\
\text { deviation }\end{array}$ \\
\hline \multirow{2}{*}{ Testing } & Pre-test & 23 & 6 & 15 & 16.9 & $65 / 3$ \\
\cline { 2 - 7 } & Post-test & 23 & 1 & 7 & $56 / 3$ & $55 / 1$ \\
\hline \multirow{2}{*}{ Control } & Pre-test & 22 & 4 & 11 & $08 / 7$ & $63 / 1$ \\
\cline { 2 - 7 } & Post-test & 22 & 2 & 9 & $48 / 6$ & $75 / 1$ \\
\hline
\end{tabular}

Levine's test results have been presented In Table 2to investigate the homogeneity of variance. According to the results in the table above, the homogeneity of variances of the two groups in scores of psychosomatic disorder, at $95 \%(\alpha=0 / 05)$ was not significant. In other words, as the insignificance of Levine's test means confirming null hypothesis, it can be concluded with $95 \%$ confidence that the variances of the two groups of test and control in the scores of psychotic disorders are the same and this premise of using analysis of covariance test in the data of the research is verified. 


\section{Table 2. Levine's Test Results to Investigate the Homogeneity of Variances in Scores of Psychosomatic Disorders}

\begin{tabular}{|l|l|l|l|l|}
\hline Coefficient & $\begin{array}{l}\text { Degrees of } \\
\text { freedom 1 }\end{array}$ & $\begin{array}{l}\text { Degrees of } \\
\text { freedom 2 }\end{array}$ & Amount of F & $\begin{array}{l}\text { The significance } \\
\text { level }\end{array}$ \\
\hline $\begin{array}{l}\text { Psychosomatic } \\
\text { disorders }\end{array}$ & 1 & 43 & $0 / 001$ & $0 / 994$ \\
\hline
\end{tabular}

In Table 3, the results of the analysis same regression slope of psychosomatic disorder coefficient have been presented as the assumption of the analysis of covariance. On the basis of the results indicated, the significant interaction (psychosomatic disorders group) is larger than $\alpha=05 / 0$, so, the regression slope homogeneity hypothesis is accepted. Due to the established nature of the assumption of the analysis of covariance, we are authorized to use this test.

Table 3.The results of the Same Regression Slope in "Psychosomatic Disorders"Scores

\begin{tabular}{llllll}
\hline Sources of variation & $\begin{array}{l}\text { Sum of } \\
\text { squares }\end{array}$ & $\begin{array}{l}\text { Degrees of } \\
\text { freedom }\end{array}$ & $\begin{array}{l}\text { Mean } \\
\text { square }\end{array}$ & $\begin{array}{l}\text { Amount } \\
\text { of F }\end{array}$ & $\begin{array}{l}\text { The significance } \\
\text { level }\end{array}$ \\
\hline Group & $0 / 22$ & 1 & $0 / 22$ & $0 / 08$ & $0 / 777$ \\
Pre-test & $63 / 04$ & 1 & $63 / 04$ & $22 / 96$ & $0 / 001$ \\
$\begin{array}{l}\text { Psychosomatic } \\
\text { Disorders Group }\end{array}$ & $2 / 73$ & 1 & $2 / 73$ & $0 / 99$ & $0 / 323$ \\
$\begin{array}{l}\text { Error } \\
\text { Total }\end{array}$ & - & & & & - \\
\hline
\end{tabular}

Hypothesis: Logical dialogue in communities of philosophical inquiry is effective on the reduction of the symptoms of psychosomatic disorders of children aged 9 to 11 years old in Tehran.

To investigate this hypothesis and to study the impact of dialoguein communities of philosophical inquiry on the symptoms of psychosomatic disorders in children aged 9 to 11 years, according to all presuppositions of the analysis of covariance (same slope of the regression line, homogeneity of variances and normal distribution), this testwas used whose test results are shown in Table 4.

Table 4. Results of the Analysis of Covariance of Different Adjusted Mean Scores of Psychosomatic Symptoms in Children in the Test and Control Groups

\begin{tabular}{lllllll}
\hline $\begin{array}{l}\text { Sources of } \\
\text { variation }\end{array}$ & $\begin{array}{l}\text { Sum of } \\
\text { squares }\end{array}$ & $\begin{array}{l}\text { Degrees of } \\
\text { Freedom }\end{array}$ & $\begin{array}{l}\text { Mean } \\
\text { square }\end{array}$ & $\begin{array}{l}\text { F } \\
\text { Ratio }\end{array}$ & $\begin{array}{l}\text { The significance } \\
\text { level }\end{array}$ & $\begin{array}{l}\text { Effect } \\
\text { Volume }\end{array}$ \\
\hline Pretest & 18 & 1 & 18 & $7 / 39$ & $0 / 009$ & $0 / 136$ \\
$\begin{array}{l}\text { Groups } \\
\text { (Independent) }\end{array}$ & $124 / 15$ & 1 & $124 / 15$ & $51 / 01$ & $0 / 001$ & $0 / 520$ \\
Error variance & $114 / 39$ & 42 & 42 & - & - & - \\
Total & 1,499 & 45 & - & & & \\
\hline
\end{tabular}

Table 4 presents the results of the analysis of covariance of the post-test by removing the effect of pre-test between the two groups. According to the results in the table, since the value of calculated $\mathrm{F}(51 / 01)$ with 1 and 47 degrees of freedom is greater than the F of table, so, the null hypothesis is rejected and the research hypothesis which mentioned logical dialoguein communities of philosophical inquiry is effective on the symptoms of psychosomatic disorders, is confirmed with 0/99 confidence. Also, according to the results of Table 4, the mean of the scores of the post-test of test group has decreased compared to the control group, which is significant. The effect of this suggests that 25 percent of the reduction of the symptoms of psychosomatic disorders of the participant in the test group can be attributed to the dialogue on philosophical stories in inquiry community. 


\section{DISCUSSION AND CONCLUSIONS}

Childhood is an appropriate time for the diagnosis of pediatric problems, early intervention, and prevention of their educational, social, and emotional problems in the future. In fact, on time intervention and modification of maladaptive behaviors of children in this critical period, in addition to the guarantees of individual mental health, enhance social skills and reduce health problems which have mental roots. The findings of the recent studies showed that students with psychosomatic disorders, after participating in communities of philosophical inquiry, based on thought-provoking stories which were consistent with their real life experiences, highly relieved the symptoms of this anxietydisorder. The Findings of this study are consistent withthe research done by PEI-Fen Liao (2013) invocational high schools in Taiwan. Liao examined the effect of participation in communities of philosophical inquiry on the reduction of the anxiety of learning English and showed that the anxieties of students who participate in these communities are significantly reduced compared to the control group. Furthermore, improving reading comprehension and learning motivation of students participating in the discussion showed a significant increase compared to the control group; these perception and enthusiasm,in turn, have been effective onthe reduction of their anxiety. Also the Findings of this study are appropriate with the research done by Shatalebi and Hedayati (2013) in 11-12 age girls in Tehran. Therefore we conclude that holding the Philosophy for Children Program in schools can reduce psychosomatic symptoms in both of gender.

When the anxiety of children to provide the correct answer disappears, and they find their logical ideas valuable, they often surprisetheir teachers by making comments about the logic understanding and implications of the stories (Haynes \&Murris, 2009). When the child sees school environment as a place to judge his value with score, lack of interest in education and training and test anxiety may decline to a minimum, and, hence, physical problems with mental root disappears.

On the other hand, based on cognitive viewpoint, anxiety disorders, including psychosomatic disorders, are the result of irrational thinking, especially falseand particularly irrational exaggerated beliefs (Azad, 2005, 1988).Kalantari (2009), along with the results of recent research,in a study entitled "the effectiveness ofphilosophy education program to children on the reduction of irrational thinking" showed that 'philosophy for children'program significantly reduced irrational thoughts in the test group. Accordingly, it can be expected that by the recession of irrational beliefs in the minds of students, the symptoms of anxiety disorders in them reduces too.

According to the results of this study and similar ones about the psychological consequences philosophy programs for children on their personal and interpersonal growth, and improving their rational beliefs, one can spread the need to change the academic space from and environmental authority, which expands negative competition and militancy pattern, to a collaborative atmosphere which encouragescollaborative learning. Expandingprograms that promote the child's challenging mind to find meaning in life, and, in a communal space without fear andjudgment, lead him towards independence and subjective judgment based on rational criteria, can reduce the academic lack of interest among students.

Therefore, planners and educational authorities are recommended to changerough, authoritative, teacher-centered, and test-oriented spaces into communities for exploring and discovering, student-centered, rational, multi-purpose in training bio-psycho-social human organism;first, through reducing educational intimidating atmosphere, help the child to relax and heal his psychological and physical problems, and,second, through creating a competitive and cooperative rather than competitive environment, help to develop the social status and grow caring though and community based. It should be mentioned that, due to the limitations of the present study, generalizing the findings of the current study to the whole statistical community, or, in other words, approving the effect of logical dialoguein inquiry community on the reduction of psychosomatic disorders requires further research on the different age and sex groups. 


\section{References}

[1] Achenbach, T. M., \&Rescorla, L. A. (2001). Manual for the ASEBA School-Age Forms \& Profiles. Burlingron, VT: University of Vermont, Research Center of Children, Youth \& Families.

[2] Achenbach, T. M., Dumenci, L., \&Rescorla, L. A. (2001). Ratings of Relations Between DSM-IV Diagnostic Categories and Items of the $C B C L / G-18, T R F$, and YSR. Online. Available in PDF Format at: www.ASEBA. Org/research/DSM 6- 18/ ratings. [accessed 15 may 2004]

[3] Azad, Hosein. (2005). Psychopathology. Tehran: Besat Publication.

[4] Bahrami, Fatemeh et al. (2007). The Relationship BetweenAnxious Thoughts and Metacognitive Beliefs in High School Students with Generalized Anxiety Disorder. Journal of Psychiatry and clinical psychology: thinking and behavior. Fall 2007; 13 (3 (sequence 50)): 249-255.

[5] Behdani, F. (2012). ComparingAnxiety Levels inRural and Urban High School Students in Mashhad. Journal of Mental Health. Mashhad University of Medical Sciences, Winter 2012, Volume 14,Number 56 , pages 294- 301.

[6] Delavar, Ali. (2006). Applied Probability and Statistics in Psychology and Education. Tehran: Roshd Publication.

[7] Fergusson DM, Horwood LJ, Lynskey MT. (1993). EarlyDentineLeads Levels and Subsequent Cognitive and Behavioral Development. Child Psychology Psychiatry J; 34(2): 215-27.

[8] FesslerDavid J. et al. (2005). Help Me, I am Down: How to Prevent andTreat Depression in Children and Adolescents. Translated byNasrinParsa. Tehran: Roshd Publication.

[9] Fisher, Robert. (2006). Teaching Children to Think. Translated byMasoudSafaeimoqadam andAfsanehNajarian. Ahvaz. RaseshPublication. (First Published in 2004).

[10] Flammer E, Alladin A. 2007. The Efficacy of Hypnotherapy in the Treatment of Psychosomatic Disorders: Meta-analytical Evidence.International Journal of Clinical and Experimental Hypnosis 55(3):251-174.

[11] Gini, Gianluca\&Pozzoli, Tiziana(2013). Bullied Children and Psychosomatic Problems: A Meta-analysis. Pediatrics:

http://pediatrics.aappublications.org/content/early/2013/09/11/peds.2013-0614

[12] Haven, Kendall (2007).Story Proof: The Science Behind the Startling Power of Story.CA:Libraries Unlimited.

[13] Haynes, J. \&Murris, K. (2009) 'The Wrong Message: Risk, Censorship and the Struggle for Democracy in the Primary School', Thinking, Journal of Philosophy for Children, 19(1): 2-11.

[14] Hedayati, M., (2011). Philosophy for Children and Controlling Aggression. Biannual Research Journal of Child and thinking, second year, first issue, Spring and Summer, 2011.

[15] Hedayati, M., et al. (2010 a). Investigating the Effects of Philosophy Program for Children as a Research Community on Improving Self-esteem in Elementary School Children from the Perspective of Teachers. Journal of Consulting (Consulting News and research). Fall 2010. 9 (35): 23-47.

[16] Hedayati, M., et al. (2010 b). Thoughtful Child, Effective Interpersonal Relationships. Biannual Research Journal of Child and thinking, first year, number one, spring and summer of 2010.

[17] Hedayati, M., et al. (2012). Growing Spiritual Intelligence through Philosophy Program for Children. Biannual Research Journal of child and thinking, third year, first issue, Spring and Summer 2012. 
[18] Kalantari. (2009). Evaluating the Effectiveness of PhilosophyPrograms to children on the Reduction of Illogical Thoughts of Girl Students in the First Grade of Middle School in BoroujenCity. MA Thesis.University of Education. Psychology, Alzahra University. 2009.

[19] Kashani JH, Orvaschel H. (1990). A Community Study of Anxiety in Children and Adolescents.Am J Psychiatry, 147: 313-18.

[20] Kendall PC, Compton SN, Walkup JT, Birmaher B, Albano AM, Sherrill J, et al. (2010). Clinical Characteristics of Anxiety Disordered Youth. J Anxiety Disord, 24(3): 360-5.

[21] Kendall-Tackett K. (2010a). Treatments for Depression that Lower Inflammation: Additional Support for an Inflammatory Etiology of Depression. In: Kendall-Tackett K, editor. The Psychoneuroimmunology of Chronic Disease: Exploring the Links Between Inflammation, Stress, and Illness. 1st ed. Washington (DC): American Psychological Association. p. 219-242.

[22] Liao, Pei-Fen. (2013).Effects of Integrating Philosophy for Children into English Picture Book Teaching on Vocational High School Students ${ }_{i}$ English Learning Motivation and Learning Anxiety.

http://pc01.lib.ntust.edu.tw/ETD-db/ETD-search/view_etd?URN=etd-0618113-144732

[23] Lipman, M. (2003).Thinking in Education. Cambridge University, press.

[24] Lipman, M. Sharp, A. M. and Oscanyan. F.S. (1980). Philosophy in the Classroom. Philadelphia: Temple university press.

[25] Marashi, Seyyed Mansour et al. (2007). Investigating the Effect of Research Community on Growing Reasoning Skills in Girl Students of Third Grade of Middle School.Tehran Curriculum Studies Quarterly, Winter 2007, Issue 7, pages 95 to 122.

[26] Minae, A. (2005). Handbook for forms of school-age measurement system based on Achenbach's experience, Tehran: Iranian Institute for Exceptional Children.

[27] Sadeghian A, Mahnaz MK, GorgiS(2010). StudyingMental Health Status in High School Female Students in HamedanCity. J Hamadan University Medical Science, 17 (3): 39-45.

[28] Thayer JF, Brosschot JF. 2005. Psychosomatics and psychopathology: Looking up and down from the brain. Psychoneuroendocrinology 30(10):1050-1058. 